\title{
Possible Factors Behind Discrepancies in Export LC Documents: A Survey of ICI-500 Companies in Turkey
}

\author{
Veysel Kula \\ Faculty of Economics and Administrative Sciences \\ Afyon Kocatepe University \\ Letife Ozdemir \\ Bolvadin School of Applied Sciences \\ Afyon Kocatepe University, Turkey \\ N. Serap Vurur \\ Bolvadin School of Applied Sciences \\ Afyon Kocatepe University, Turkey
}

\begin{abstract}
Letter of credit (LC) is a frequently used payment mechanism in international trade and is traditionally regarded as the assurance of payment for exporters. LC process requires exporters to submit to banks documents that are in compliance with the terms of LC. Strict compliance principle mostly results in the rejection of the documents by the banks, thus jeopordazing the collection of the proceeds of the sales by the exporters. Drawn on the data obtained through survey from 460 ICI 500 list companies in Turkey, this study attemts to explore the possible reasons behind the discrepancies in the documents presented by the exporters. Ordered logit regression analysis results indicate that the tendency of importers, as perceived by exporters, to waive discrepancies and the difficulties in complying with sales contract terms have statistically significant positive relationship with the extent of discrepancies. On the other hand, competency of the export personnel results in lesser amount of discrepancy.
\end{abstract}

Keywords: Letters of credit, Document discrepancy, Strict compliance principle, Ordered logit regression, Turkey.

\section{INTRODUCTION}

International trade has inherent risks for importers and exporters due to different legal systems and conventions, governmental interferences and transactors' inability to know enough each other. Letter of credit (hereinafter LC) is a tool providing simultaneous protection for both importers and exporters by utilizing the banks' reputation in international transactions.

LC mechanism provides benefits to the exporters as they are entitled to a guaranteed payment following the presentation to the bank of complying documents. But the high frequency rates of discrepancies in the documents presented to the banks create negative impacts on LC as a guaranteed payment mechanism. The present study aims at empirically investigating the possible causes of discrepancies in export documents. For this purpose, a survey was 
Kula, V., Ozdemir, L., \& Vurur, N. S. (2015). Possible Factors behind Discrrepancies in Export LC Documents: A Survey of ICI-500 Companies in Turkey. Archive of Business Research, 3(1) 123-131.

conducted on 460 companies in Istanbul Chamber of Commerce 500 List Companies (ICI 500). Sample frame, thus, features a capacity to reflect the pervasiveness of the findings for wellknown, large scale industrial companies with a letter of credit experience in Turkey.

The following second section of the study will inquire the basic operating process of the LC as a payment mechanism in international trade together with the implication of the non-complying documents in the process. The third section will provide literature review. The fourth section will present the methodology and the results of the survey study. The study will end by the summary and conclusion section.

\section{LETTER OF CREDIT AS A PAYMENT MECHANISM}

By attributing to banks prominent position, LC facilitates international trade for both importers and exporters. Following the application of importers before the shipment, banks issue letter of credit in which the the types and the contents of the required documents are specifically stipulated. As Weissman (1996) indicates, in issuing LC, the buyer's bank substitutes its credit standing for that of the buyer. Exporters, then knows that, upon submitting the documents as per the terms of credit, they will deserve the right to collect export proceeds from the bank. The benefit provided to the importer by LC is that importer feels confident that it will collect the goods once the banks take up compliant documents from exporters.

There is no governmental body regulating LC process. But, International Chamber of Commerce, a private international organization headquartered in Paris, promulgates the rules about LC process. As Todd (1993: 24) puts forward, originally published in 1933, these rules were revised in 1951, 1962, 1974, and 1983 and in 1993. As the recent one, the sixth revision has been in effect since 2007 under the name of UCP No.600 (ICC, 2007).

The second article of the UCP No.600 defines the letter of credit as "any arrangement, however named or described, that is irrevocable and thereby constitutes a definite undertaking of the issuing bank to honour a complying presentation" (ICC, 2007). As stressed in the definition, the documents presented by the exporters to the banks must be complying. Otherwise, in case of discrepant documents, exporters will lose the right to collect proceeds, or will be left to rely on the mercy of importers to waive the discrepancies.

The doctrine of "strict compliance" is one fundemantal principle of the letter of credit instrument (Zhang, 2012: 344). However, as Hashim (2103) emphasizes, despite being the fundamental principle underlying LC transactions, the requirement for strict compliance is not mentioned in any versions of the UCP. That is, UCP does not feature any yardstick regarding the extent of discrepany that would justify the banks to refuse the documents on noncompliance grounds. The task of determining standard of compliance required in the documents, therefore, is left to the courts to decide (Hashim, 2013). As indicated by Kraaovska (2008), courts all over the world have not cured the deficiencies in the application of the rules. While some courts approach "strict compliance" in less stringent terms, others predicate a robotic approach, which treats the examination of documents as a proofreading exercise. Banks are observed, as Kraaovska (2008) says, to require the documentary compliance as strict as it is required by the applicants and courts, because the UCP rules do not provide a safe guide in this matter.

Discrepancy rates continue to be in the 60 to 80 percent rate (Baker, 2000). A bank manager in the USA even reported a discrepancy rate of $98 \%$ for their import LC transactions (Collyer, 
2009). Collyer (2009) puts forward the fact that document refusals, due to discrepancies, have become a daily activity for banks on a global basis. The introduction part of the UCP 600 (ICC, 2007 ) cites that because of discrepancies, approximately $70 \%$ of documents presented under the LC were being rejected on first presentatiton. UCP 600 (ICC, 2007) further voices the concern that discrepancy rate has a negative effect on the LC being seen as a means of payment and, if unchecked, could have serious implications for maintaining or increasing its market share as a recognized means of settlement in international trade.

There is a wide array of reasons for rejecting documents due to non-compliance, ranging from misspellings and typographical errors (Kraaovska, 2008) to miunderstandings in how to prepare documents (Baker, 2000). Baker (2000) provides twenty examples of discrepancies including documents being inconsistent with each other, and drafts with no signitare or endorsement. In his study of discrepancies in 500 LC transactions by five USA banks, Mann (2000) found out defective documents as the most common discrepancy type, followed by missing documents, late shipment and late presentation.

The review of literature has revealed no statistical study exploring the factors leading to discrepancies. However, the possible causes of discrepancies are could easily be featured descriptively. For example, contractual defaults, complex technical provisions of LC, strict attitude of banks in document evaluation might logically result in discrepanices. Moreover, lenient attitude expected of importers could let exporters lack diligence and due care in document preparation. The next part of the study will provide the findings of literature review about the factors that influence the amount of discrepancy in LC documents.

\section{LITERATURE REVIEW}

This study aims at finding the possible factors leading to discrepant documents in export LC documents by using ordered logit regression.

Descriptive evaluation of the relevant factors has been discussed in previous studies. One typical factor appears to be the clauses in the sales contract. As a rule, the letter of credit mechanism by its nature is a separate contract from the sale or other contract (ICP No.600, Art.4). But, as Zhang (2012) puts forward, usually LC clauses in a LC agreement are essentially based on an underlying international sales contract. That means that contracting clauses specifically the ones on the various documents such as bill of lading, insurance policy and commercial invoice must be clearly stipulated in the sales contract. In a study on a sample of 500 LC documents in the USA by Mann (2000), more than a quarter of presentations that contained discrepanices appeared to suggest a contractual default by the seller, that is, a failure to comply with the substantive provisions of the underlying sales contract.

The introductory part of UCP 600 (ICC, 2007) refers to the discrepancy fee imposed by the banks as a possible cause of especially dubious or unsound discrepancies. Apart from revenue considerations, banks may adopt strict attitude in document evaluation to safeguard themselves in potential legal cases. Banks will be protected, as Hashim (2013) indicates, against any legal repercussion as long as the payment to the seller was made upon strict compliance of sellers' documents. Hence, motivated either to earn revenue or not to lose a legal case to be brought by buyers, banks might employ robotic approach, even not tolerating infinitesmall and logical differences in the documents.

LC is in itself complicated and risky (Zhang, 2012). Discrepancies might arise because of a failure by exporters to produce documents in compliance with the technical provisions of the letter of credit. Most of the time, those defects do not imply any contractual default. An 
inadequate signature on a bill of lading, or a technical inaccuracy in describing the collateral are two common examples. The poor fit between discrepancies and default is, in fact, a problem with the LC system (Mann, 2000). Moreover, the buyers, in order to deter seller fraud, may insert detailed, complex documentary requirements in LC (McLaughlin, 1989).

As Zhang (2012) suggests, choosing a credible trading partner is the best way of avoiding falling into a harmful situation. It is natural to expect credible importers to waive discrepancies as long as the discrepancies do not imply default on the contractual agreements. In fact, when banks decide that the documents are discrepant, they let the buyers know the case, If buyers ask the banks to waive the discrepancies, the bank can accept the documents. This expectation might lead the exporters to exert their efforts primarily for meeting the sale contract requirements, and not overemphasize document preparation.

LC is a process requiring specialization. For accessing to payment, document preparation is more important than the export product quality. Baker (2000), firstly emphasizing that preparation of LC documents seem arcane and laborious, points out to the importance of qualified personal in preparing error-free documents.

In his seminal work entitled "The role of letters of credit in payment transactions" published in August 2000 issue of Michigan Law Review, Ronald J. Mann asserted an alternative explanation for the use of LC. Mann speculates one major justification as for what the banks verify: verifying to the exporter the likelihood that the importer will pay. By using LC, the importer rents the issuing bank's reputation to allow the exporter to verify the credibility of the importer's promise to make payment when the exporter ships the goods. In addition to the the relative ease of verifying the reliability of a foreign bank as opposed to an importer and the quality of information that the bank is in position to provide, banks, by issuing LC, vouch for the future performance of the buyer. Mann's (2000) conviction arising from his discussion with bank managers is that banks engage in a serious of screening process of customers for whom they issue letters of credit and they are rather disinclined to issue letter of credit for the customers that are to refuse to waive discrepancies in letters of credit. Based on its past interactions with the importer, the bank is able to assess the importer's general probity as to whether the importer will perform according to industry norms in the letter of credit transaction. Additionally, by issuing letter of credit the bank implies to assert that it can influence the importer's behavior on her willingness to waive discrepancies. From the perspective of the exporter, the ability of the bank to influence the conduct of the overseas importer might comprise the most important aspect of the letter of credit (Mann, 2000).

In sum, the review of literature indicates some factors with capacity to affect the amount of discrepancies in the documents presented by the exporters. Those factors with their respective labels in the incoming regression analysis is as follows: the extent of difficulty in complying with the requirements stipulated in the sales contract (CONTRACTUAL-REQUIREMENTS), stringency of the attitude of the banks in document evaluation (BANK-ATTITUDE), inherent technical complexities of LC process (COMPLEXITY), expected attitude of importers to waive the discrepancies (IMPORTERS-WAIVING), competency of the employees of the export company responsible for document preparation (COMPETENCY) and presumed capacity of issuing banks to verify the reliability of importers (VERIFICATION). 


\section{Research Methodology}

\section{RESEARCH FINDINGS}

The present study aims to specify the factors affecting the level of discrepancies in the LC documents by collecting primary data based on a questionnaire survey from the companies with a letter of credit experience in Istanbul Chamber of Industry 500 (ICI 500 list). Since 1968 Istanbul Chamber of Commerce has been issuing the list of largest industrial companies in Turkey. The list is formed based on sales volume. The companies in the list are representatitive of large scale industrial companies in Turkey. In addition to the ICI 500 list, which is the sampling frame of this study, ICI produces a second group of companies under the name of ICI Second Top List.

A professional survey services company was contracted in 2013 to conduct the survey. Firstly, the names and the contact information of the ICI 500 companies were obtained from the web site of ICI. Consequently, this set of information together with the questionnaire form was forwarded to the survey services company.

The survey company attempted to contact all companies in the ICI 500 list either via phone or in person. Of 500 companies, 460 participated in the survey, representing $92 \%$ participation rate. Only 40 companies rejected to participate in the survey.

\section{Descriptive Statistics}

The sample companies are located in Marmara Region (59.4\%), Central Anatolian Region (13.0\%), Aegean Region (12.2\%), Mediterrian Region (7.2\%) and other regions (8.2\%). Food, beverage and tobacco (20.22\%) chemicals, petroleum and plastic products $(15.0 \%)$, metal products (13.91) and textile-garments (10.22\%), are the main sectors emerging in the sectoral distribution of the sample.

Table 1 reports the descriptive statistics as well as the definitions of the variables used in the study. As shown in Table 1, when the statements evaluated on a Likert scale $11=$ "strongly agree, 5="strongly disagree) are considered, it is seen that there are discrepancies in LC documents, though not to a great extent (DISCREPANCY-LEVEL, 2.61 mean). The respondents have mixed feelings as to the perceived tendency of importers to waive discrepancies in the documents (IMPORTERS-WAIVING, 3.00 mean). As for the attitude of banks, the respondents agree with the statement that banks are very strict in document evaluation (BANK-ATTITUDE, 2.00 mean). On average, the sample do not think that contractual requirements in export sales are hard to comply with (CONTRACTUAL-REQIREMENTS, 3.39 mean). The sample accept that LC process has inherent technical complexities (COMPLEXITY, 2.22 mean). The members of staff responsible from LC document preparation are regarded by the sample companies as competent (COMPETENCY, 2.02 mean).

Table 1: Descriptive statistics for variables

\begin{tabular}{|c|c|c|c|c|c|c|c|}
\hline Variables & Description & Mean & Median & Max. & Min. & SD & \# of obs. \\
\hline DISCREPANCY-LEVEL* & $\begin{array}{l}\text { Evaluation of the statement of "In } \\
\text { general, there are discrepancies } \\
\text { in LC document we submit" }\end{array}$ & 2.61 & 2 & 5 & 1 & 1.02 & 389 \\
\hline IMPORTERS-WAIVING* & $\begin{array}{l}\text { Evaluation of the statement of } \\
\text { "In general, we expect importers } \\
\text { to waive discrepancies in LC" }\end{array}$ & 3.00 & 3 & 5 & 1 & 1.07 & 407 \\
\hline BANK-ATTITUDE & $\begin{array}{l}\text { Evaluation of the statement of } \\
\text { "We think that banks are very } \\
\text { strict in document evaluation" }\end{array}$ & 2.00 & 2 & 4 & 1 & 0.58 & 409 \\
\hline CONTRACTUAL- & Evaluation of the statement of & 3.39 & 4 & 5 & 1 & 0.98 & 409 \\
\hline
\end{tabular}


Kula, V., Ozdemir, L., \& Vurur, N. S. (2015). Possible Factors behind Discrrepancies in Export LC Documents: A Survey of ICI-500 Companies in Turkey. Archive of Business Research, 3(1) 123-131.

\begin{tabular}{|c|c|c|c|c|c|c|}
\hline REQIREMENTS* & $\begin{array}{l}\text { "Contractual requirements are } \\
\text { hard to comply with" }\end{array}$ & & & & & \\
\hline COMPLEXITY* & $\begin{array}{l}\text { Evaluation of the statement of } 2.22 \\
\text { "LC process features several } \\
\text { technical complexities" }\end{array}$ & 2 & 4 & 1 & 0.70 & 406 \\
\hline COMPETENCY* & $\begin{array}{l}\text { Evaluation of the statement of } 2.02 \\
\text { "We have staff competent in LC } \\
\text { document preparation" }\end{array}$ & 2 & 4 & 1 & 0.46 & 400 \\
\hline VERIFICATION & $\begin{array}{l}\text { Evaluation of the statement of } 44.58 \\
\text { "By issuing LC, banks verify the } \\
\text { reliability of importers". }\end{array}$ & 50 & 100 & 0 & 20.05 & 296 \\
\hline
\end{tabular}

*The statements are evaluated on a scale from 1="strongly agree" to 5=strongly disagree"

Based on the full-scale of 100 points, the respondents think that the verification capacity of letter of credit as to the reliability of importers (VERIFICATION) is 44.58 percent. This finding reveals that in the opinion of the respondents, LC issuance by banks does, in fact, not prevalently serve as a tool to indicate the reliability of importers.

\section{Ordered Logit Regression Results}

The level of discrepancy in export LC documents as perceived by the respondents (DISCREPANCY-LEVEL) is regressed on all other variables specified and defined in Table 1. As for the dependent variable, the response categories are ordered, that is ranked. In other words, the responses are measured in a Likerts-scale ordered from " 1 =strongly agree" to " $5=$ strongly disagree". Although there is clear ranking among five response categories, they can not be treated as interval scale or ratio scale variables. As indicated by Gujarati (2011), the ordinal logit is speficially developed to handle ordinal scale variables. Therefore, ordered logit model is estimated by means of EViews-8. The regression results are reported in Table 2. Overall, the regression results are statistically significant (LR statistics:14.13, $\mathrm{p}<0.05$ ).

There is a statistically significant positive relationship between the level of discrepancy in documents and the perceived tendency of importers to waive discrepancies (IMPORTERSWAIVING, $p<0.10$ ). This result indicates that the exporters do not seem to waste energy in producing discrepancy-free documents if they think favourably about the importers' expected waiving behaviour.

Other factor with statistically significant positive effect on the level of discrepancy is the level of difficulty exporters experience in performing sales contractual requirements (CONTRACTUAL-REQIREMENTS, $\mathrm{p}<0.05$ ). By its nature, LC is a separate and independent transaction from the sale contract. However, some of contractual requirements, such as shipment date, do naturally find place in LC requirements. Then, toughness of contractual requirements possibly posted to LC conditions is reflected as more discrepancies observed in submitted documents. 
Table 2: Results of ordered logit regression

Dependent Variable: DISCREPANCY-LEVEL
Method: ML - Ordered Logit (Quadratic hill climbing)
Sample (adjusted): 1457
Included observations: 288 after adjustments
Number of ordered indicator values: 5
Convergence achieved after 6 iterations
Covariance matrix computed using second derivatives

\begin{tabular}{|l|l|l|l}
\hline \hline Variable & Coeff. & Std Error & Z
\end{tabular}

\begin{tabular}{|l|l|l|l|l||}
\hline IMPORTERS-WAIVING* & Coeff. & Std Error & $\begin{array}{l}\text { Z } \\
\text { Statistics }\end{array}$ & Prob. \\
\hline $\begin{array}{l}0.19884 \\
7\end{array}$ & 0.115689 & 1.718808 & $0.0856^{*}$ \\
\hline BANK-ATTITUDE & $\begin{array}{l}0.01646 \\
4\end{array}$ & 0.216778 & 0.075950 & 0.9395 \\
\hline
\end{tabular}

\begin{tabular}{|l|l|l|l|l||}
\hline CONTRACTUAL- & 0.33147 & 0.132493 & 2.501862 & $0.0124^{* *}$ \\
REQIREMENTS* & 8 & & & \\
\hline COMPLEXITY*
\end{tabular}

\begin{tabular}{|l|l|l|l|l|l}
\hline COMPLEXITY* & 0.20991 & 0.165211 & 1.270577 & 0.2039 \\
\hline
\end{tabular}

\begin{tabular}{|l|l|l|l|l|}
\hline & 3 & & & \\
\hline COMPETENCY* $^{*}$ & - & 0.324908 & -1.627474 & $0.1036^{*}$ \\
& 0.52877 & & & \\
\hline VERIFICATION & 0.00177 & 0.006171 & 0.286885 & 0.7742 \\
& 0 & & & \\
\hline \hline
\end{tabular}

\begin{tabular}{|l|l|}
\hline Pseudo R-squared & 0.02630
\end{tabular}

\begin{tabular}{|l|l|}
\hline Log likelihood & 6 \\
\hline LR statistic & -261.585 \\
\hline
\end{tabular}

\begin{tabular}{l|l|} 
& 8 \\
\hline Prob(LR statistic) & 0.02816 \\
\hline
\end{tabular}

The dependent variable is the level of discrepancy in LC documents (DISCREPANCY-LEVEL) Probabilites; *, **indicate significance at $10 \%, 5 \%$ respectively.

According to the ordered logit regression results, the availability of competent staff for LC operations (COMPETENCY) has statistically significant negative relationship with the amount of discrepancy, though the statistical significancy is not so strong standing at limits $(\mathrm{p}=0.1036)$. The result sounds plausible in that expert personnel will mean the production of less problematic documents. As the results of the regression display, no other statistically significant relationship exists between the amount of discrepancy and the remaining independent variables, namely, tough attitude of banks in document evaluation (BANKATTITUDE), technical complexity of LC process (COMPLEXITY), and the indicative role of the issuance of LC as to the reliability of importers (VERIFICATION).

\section{SUMMARY AND CONCLUDING REMARKS}

LC is a commonly used payment mechanism in international trade. The buyers and sellers in international trade are physically located at far distant places from each other, lessening the information flow and trust between the parties. If LC is employed as a payment method, then banks emerge as a third party with pivotal role to the international transaction. Banks, in fact, lend their credibility to the transaction. When the issuing bank establishes LC in favor of exporter, the banks bond themselves to make the payment against the presentation, by the exporter, of the documents stipulated in LC. However, the statistics reveals that around 70 percent of first presentations contain discrepant documents. The study attempts to investigate the reasonds behind discrepancies in export LC documents by conducting a survey study on companies listed in Istanbul Chamber of Commerce (ICI) 500 list, representing the largest 
industrial companies located throughout Turkey. Ordered regression results yield interesting findings.

The subjective evaluation, by the respondents, of the extent of discrepancies in LC documents reveals that there are discrepancies in the documents the sample companies present to banks. However, the degree of agreement as to this effect is not too strong. This may be the result of the nature of the sample companies as they are the largest companies in Turkey with possible long experience in international trade and LC transactions. For smaller companies, it is natural to have higher level of discrepancies in LC documents.

Of all independent variables employed in the regression, only three have statistically significant influence on the level of discrepancy. Firstly, there is a statistically significant positive relationship between the level of discrepancy in documents and the perceived tendency of importers to waive discrepancies. This finding confirms the assertion by Baker (2000) that if the exporter is comfortable with their relationship with the buyer and think that there is no real danger the importer will refuse to pay, the exporter can forward the documents with discrepancies to the issuing bank for approval. The result supports the viewpoint of Corre (2001) who claims that there is a good reason to expect a rational buyer to waive the conditions, at least in cases where the seller seems to have performed the underlying contract adequately.

The second factor with statistically significant positive effect on the level of discrepancy is the level of difficulty exporters experience in performing sales contractual requirements. This finding is in conformity with the finding by Mann (2000). Although LC is a separate and independent transaction from the sale contract, some of contractual requirements naturally appear as LC requirements, too. Late shipment, inconsistent shipment terms, inconsistent document types are possible exemplary discrepancies that might arise because of violating sale contract.

Thirdly, the availability of competent staff for LC operations has statistically significant, though not too strong, negative relationship with the amount of discrepancy. The result sounds plausible as expert personnel will mean higher probability of producing error-free documents. Recognizing the strategic importance of complying documents in LC mechanism, Baker (2000) even suggests outsourcing document preparation process. The author provides examples of companies that guarantee that documents that they prepare will comply with the LC. Hence, the use of companies specializing in document preparation will allow faster payment.

As the results of the regression display, no other statistically significant relationship exists between the amount of discrepancy and the remaining independent variables, namely, tough attitude of banks in document evaluation, technical complexity of LC process, and the indicative role of the issuance of LC by banks as to the reliability of importers.

LC is a payment method that seems not to lose its importance in international trade in future. The largest firms in Turkey constituted the sampling frame of this study. Hence, the findings can not be generalized to smaller firms. Future studies could concentrate on uncovering the differences between large and small firms with respect to the causes of discrepancies. The present study restricted its sample frame to the exporters. Utilization of data from importers can be suggested for future studies on the subject. 


\section{NOTES}

This study is financially supported by the Scientific Research Commission of Afyon Kocatepe University, Turkey, under the project No: 11IIBF01.

\section{References}

Baker, W. (2000). Dealing with Letter of Credit Discrepancies, Business Credit, 102(10) November/December, $42-$ 47.

Collyer, G. (2009), the curse of the 'spurious' discrepancies, I: 27 July, (http://www.coastlinesolutions.com/issue27.htm).

Corre, J. I. (2001), Reconciling the Old Theory and the New Evidence, Michigan Law Review, Vol. 98 2494, 25482553.

Gujarati, D. (2011), Econometrics by Example, Palgrave Macmillan, 2011, USA.

Hashim, R. C. (2013). Principle of Strict Compliance in Letter of Credit: Towards a Proper Standard of Compliance, 6 November 2013, (http://kibar.blogspot.com.tr/2013/11/article-principle-of-strict-compliance.html).

International Chamber of Commerce. (2007). Documentary Credits: UCP 600, Paris.

Kraåovska, D. (2008). Impact of the Doctrine of Strict Compliance on a Letter of Credit Transaction, Master Thesis, University of Aarhus, Aarhus School of Business, 76.

Mann, R. J. (2000). The Role of Letters of Credit in Payment Transactions, Michigan Law Review, Volç98 2548, 2494-2536.

McLaughlin, G. T. (1989). Structuring Commercial Letter of Credit Transactions to Safeguard the Interests of the Buyer, Uniform Commercial Code Law Journal, 21(318), 318-332.

Todd, P. (1993). Bills of Ladings and Banker's Documentary Credits, Lloyd's of London Pres LTD.

Weissman, I. (1996). Letters of Credit: Doing Business in a Global Market, CPA Journal, 66(1), 46-50.

Zhang, Y. (2012), Documentary Letter of Credit Fraud Risk Management", Journal of Financial Crime, 19(4), 343 354. 